\title{
Correction to: Omega-3 Fatty Acids and Gut Microbiota: A Reciprocal Interaction in Nonalcoholic Fatty Liver Disease
}

\author{
Samaa Shama ${ }^{1,3,4} \cdot$ Wanqing Liu ${ }^{1,2,4}$
}

Published online: 24 March 2020

(c) Springer Science+Business Media, LLC, part of Springer Nature 2020

\section{Correction to: \\ Digestive Diseases and Sciences (2020) 65:906-910 https://doi.org/10.1007/s10620-020-06117-5}

The original version of the article is unfortunately missing the Acknowledgments section. Acknowledgments section is given below.

\begin{abstract}
Acknowledgments This work is supported in part by NIH/NIDDK R01 DK106540) (W.L.). S.S. is a visiting scholar supported by the Egyptian Ministry of Higher Education and the Egyptian Cultural Affairs and Missions Sector, Egypt
\end{abstract}

Publisher's Note Springer Nature remains neutral with regard to jurisdictional claims in published maps and institutional affiliations.

The original article can be found online at https://doi.org/10.1007/ s10620-020-06117-5.

Wanqing Liu

wliu@wayne.edu

1 Department of Pharmaceutical Sciences, Eugene Applebaum College of Pharmacy and Health Sciences, Wayne State University, Detroit, MI, USA

2 Department of Pharmacology, School of Medicine, Wayne State University, Detroit, MI, USA

3 Department of Molecular Drug Evaluation, National Organization of Drug Control and Research, Giza, Egypt

4 iBio Center 2401, Wayne State University, 6135 Woodward Ave, Detroit, MI 48202, USA 